\title{
Management of cataract in a patient with anterior megalophthalmos
}

\author{
Syed Bilal Hassan Zaidi, ${ }^{1}$ Kirk A J Stephenson 지, ${ }^{1}$ Hafiz Muhammad Ejaz-Ul-Haq, ${ }^{2}$ \\ Hassan Massanna ${ }^{3}$
}

${ }^{1}$ Ophthalmology, Mater Misericordiae University Hospital, Dublin, Ireland ${ }^{2}$ Ophthalmology, Southend University Hospital NHS Foundation Trust, Westcliff-onSea, UK

${ }^{3}$ Department of Ophthalmology, Al-Shifa Trust Eye Hospital Rawalpindi, Rawalpindi, Pakistan

Correspondence to Dr Kirk A J Stephenson; kirkstephenson@hotmail.com

Accepted 10 February 2021

\section{DESCRIPTION}

A healthy 40-year-old man presented with reduced (counting fingers) right eye visual acuity (VA) due to a dense unilateral cataract (posterior subcapsular and nuclear sclerosis) (figure 1A). Examination revealed bilateral enlarged but thin corneas and deep anterior chambers (ACs) (table 1). Bilateral iridodonesis and phacodonesis were noted with no significant subluxation of the right crystalline lens. Iridocorneal angles were open bilaterally with normal intraocular pressures (12 and $14 \mathrm{~mm} \mathrm{Hg}$, right and left, respectively) (figure 1C). Corneal diameters were $14.5 \mathrm{~mm} / 14.5 \mathrm{~mm}$ and $15 \mathrm{~mm} / 15 \mathrm{~mm}$, right and left, respectively, in horizontal and vertical meridians (figure 1D). There was no view of the fundus in the right eye, but the left eye posterior segment was normal without stigmata of vitreoretinal degeneration. B-scan ultrasonography excluded major right eye posterior segment pathology. Megalocornea, extremely deep AC and zonular laxity, without sequelae of congenital glaucoma (ie, raised intraocular pressure and optic neuropathy), suggested a diagnosis of anterior megalophthalmos (AM). Cataract surgery for visual improvement was discussed and consented for by the patient.

Cataract extraction in AM presents a number of surgical challenges. Extreme AC depth makes access to the cataract difficult, but this was bypassed by supracapsular prolapse of the lens nucleus out of the capsular bag also minimising shear stress on the weakened zonules of Zinn. Intraocular lens (IOL) choice in such a large eye was another challenging factor, and a +13.00 dioptre Rayner Superflex IOL (12.5 mm diameter, Rayner Intraocular Lenses Limited, UK) was implanted in the capsular bag with reverse optic capture technique. VA on the first postoperative day was $6 / 6$, which was maintained at

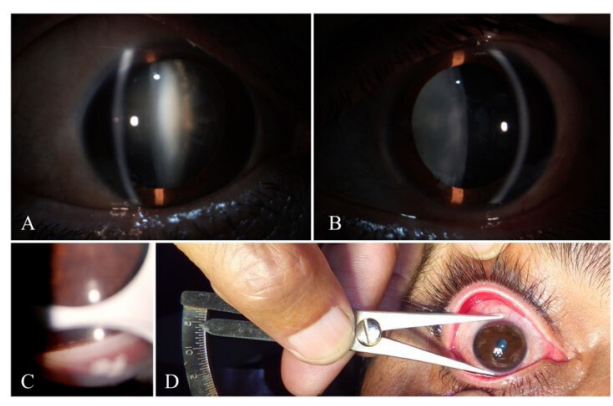

Figure 1 (A) Slit lamp image of the anterior segment of the right eye showing a dense cataract in an eye with an exceptionally large cornea (megalocornea) and very deep anterior chamber. (B) Slit lamp image of the left eye showing megalocornea and deep AC with mild cataract. (C) Gonioscopy image of the right eye iridocorneal angle confirming a normal, open angle. (D) Vertical corneal diameter of the right eye, measured at $14.5 \mathrm{~mm}$.

6-month review. This is the first case report of AM in Pakistan.

First reported in 1914, AM is defined as megalocornea with deep AC without abnormal axial length. ${ }^{1}$ Elongation of the ciliary ring causes irislens-diaphragm instability (ie, phacodonesis and iridodonesis), predisposing to lens subluxation (crystalline lens and IOLs). ${ }^{2}$ IOL choice is critical in such a large eyes and deep ACs with weak, stretched zonules. The main lens issues in AM are instability of standard diameter IOLs (ie, $13 \mathrm{~mm}$ ) within the abnormally large capsular bag, lack of optic centration and postoperative posterior dislocation of IOLs. ${ }^{3-5}$ Cases of IOL dislocation with endocapsular fixation have been described. ${ }^{3}$ Multiple IOL strategies have been employed, including iris-claw
Check for updates

(C) BMJ Publishing Group Limited 2021. No commercial re-use. See rights and permissions. Published by BMJ.

To cite: Zaidi SBH,

Stephenson KAJ,

Ejaz-UI-Haq HM, et al. BMJ

Case Rep 2021;14:e241659.

doi:10.1136/bcr-2021-

241659
Table 1 Biometric parameters of the eyes in this anterior megalophthalmos case

\begin{tabular}{llcc}
\hline Parameters & Right eye & Left eye & Normal range \\
\hline Axial length & $24.16 \mathrm{~mm}$ & $24.19 \mathrm{~mm}$ & $22-26 \mathrm{~mm}$ \\
AC depth & $6.39 \mathrm{~mm}$ & $5.81 \mathrm{~mm}$ & $1.5-4 \mathrm{~mm}$ \\
Lens thickness & $4.00 \mathrm{~mm}$ & $4.04 \mathrm{~mm}$ & $4 \mathrm{~mm}$ \\
White to white distance & $15.0 \mathrm{~mm}$ & $14.5 \mathrm{~mm}$ & $11-12 \mathrm{~mm}$ \\
Central corneal thickness & $475 \mu \mathrm{m}$ & $493 \mu \mathrm{m}$ & $555 \mu \mathrm{m}$ \\
K1 & $45.2 \mathrm{D}$ & $44.3 \mathrm{D}$ & $42.00-44.00 \mathrm{D}$ \\
K2 & $47.2 \mathrm{D}$ & $47.9 \mathrm{D}$ & $42.00-44.00 \mathrm{D}$ \\
\hline Preoperative refraction & Precluded by cataract & $-2.50 \mathrm{DS} /-0.50 \mathrm{DC} \times 120$ & $-6.00 \mathrm{D}$ to $+3.00 \mathrm{D}$ \\
\hline
\end{tabular}

The axial lengths (ultrasound for the right eye), anterior chamber depths, lens thickness, white to white distance, central corneal thickness and keratometry (K1 and K2) as measured by IOLMaster 700 V.1.14 (Carl Zeiss Meditec Ag, Jena, Germany) and refraction (in dioptre sphere, DS, and dioptre cylindrical, DC) are shown relative to normal reference ranges.

$\mathrm{AC}$, anterior chamber. 


\section{Learning points}

- Consider a diagnosis of anterior megalophthalmos in the presence of megalocornea, ultradeep anterior chamber and zonular laxity (ie, iridophacodonesis, ectopia lentis) without signs of congenital glaucoma or increased axial length.

- Preoperative diagnosis allows appropriate surgical planning to ensure appropriate intraocular lens (IOL) choices and promote optimal refractive and visual outcomes while avoiding IOL dislocation into the vitreous cavity.

- The surgeon must consider intraoperative challenges in anterior megalophthalmos, including accessing the cataract in an ultradeep anterior chamber, baseline zonular instability with difficult capsulorhexis and IOL considerations, in addition to standard cataract risks.

IOLs, ${ }^{6}$ iris-sutured IOLs and custom-made larger-diameter IOLs. ${ }^{5-7} \mathrm{AM}$ is associated with vitreous abnormalities (eg, syneresis, synchysis and optically empty vitreous with strands) ${ }^{8}$ and vitreoretinal pathology (eg, lattice degeneration, associated with retinal detachment); thus, annual dilated fundal examination is recommended. ${ }^{8}$ Other notable ocular associations include anterior embryotoxon, mosaic corneal dystrophy, glaucoma due to goniodysgenesis, irregular astigmatism, and amblyopia due to strabismus and myopia. ${ }^{9}$ Mutations in the Xq12-q26 region have been implicated previously. ${ }^{10}$ Systemic associations include Marfan syndrome, trisomy 21, Apert syndrome, mucolipidosis type 2 and Walker-Warburg syndrome. ${ }^{11}$

Recognition and diagnosis of AM allows planning for the monitoring of the posterior segment and preparation for the unique challenges of cataract surgery in the complex anterior segment.
Twitter Syed Bilal Hassan Zaidi @bilalzaidi88 and Kirk A J Stephenson @ KarkStaphonsen

Contributors SBHZ: patient care, manuscript drafting and revision. KAJS: manuscript drafting and revision. HME-U-H: manuscript drafting and revision. HM: patient care, manuscript drafting and revision.

Funding The authors have not declared a specific grant for this research from any funding agency in the public, commercial or not-for-profit sectors.

Competing interests None declared.

Patient consent for publication Obtained.

Provenance and peer review Not commissioned; externally peer reviewed.

ORCID iD

Kirk A J Stephenson http://orcid.org/0000-0002-7462-7725

\section{REFERENCES}

1 Wright RE. Megalophthalmus and Microphthalmus. Br J Ophthalmol 1922;6:35-7.

2 Kuchenbecker J, Behrens-Baumann W. Ciliary body dysplasia in megalophthalmos anterior diagnosed using ultrasound biomicroscopy. Eye 2002;16:638-9.

3 Wang Q-W, Xu W, Zhu Y-N, et al. Misdiagnosis induced intraocular lens dislocation in anterior megalophthalmos. Chin Med J 2012;125:3180-2.

4 Javadi MA, Jafarinasab MR, Mirdehghan SA. Cataract surgery and intraocular lens implantation in anterior megalophthalmos. I Cataract Refract Surg 2000;26:1687-90

5 Li Y, Liu F, Zhang Q, et al. Cataract surgery and intraocular lens implantation in anterior megalophthalmos. Int J Ophthalmol 2012;5:648-9.

6 Oetting TA, Newsom TH. Bilateral artisan lens for aphakia and megalocornea: longterm follow-up. J Cataract Refract Surg 2006;32:526-8.

7 Vaz FM, Osher RH, Marques Vaz F. Cataract surgery and anterior megalophthalmos: custom intraocular lens and special considerations. J Cataract Refract Surg 2007;33:2147-50.

8 Kodjikian L, Beby F, Spire M, et al. Combined pars plana phacofragmentation, vitrectomy, and artisan lens implantation for traumatic subluxated cataracts. Retina 2006;26:909-16.

9 Vail DT. Adult hereditary anterior megalophthalmus sine glaucoma: a definite disease entity with special reference to the extraction of cataract. Arch Ophthalmol 1931;6:39-62.

10 Megalocornea MFM. Clinical and genetic aspects. Doc Ophthalmol 1994;87:46-52.

11 Agrawal P, Patel C, Abidi N, et al. Walker Warburg syndrome associated with microphthalmos and megalophthalmos: a rare combination. Oman J Ophthalmol 2013;6:134-5.

Copyright 2021 BMJ Publishing Group. All rights reserved. For permission to reuse any of this content visit

https://www.bmj.com/company/products-services/rights-and-licensing/permissions/

BMJ Case Report Fellows may re-use this article for personal use and teaching without any further permission.

Become a Fellow of BMJ Case Reports today and you can:

- Submit as many cases as you like

- Enjoy fast sympathetic peer review and rapid publication of accepted articles

- Access all the published articles

- Re-use any of the published material for personal use and teaching without further permission

Customer Service

If you have any further queries about your subscription, please contact our customer services team on +44 (0) 2071111105 or via email at support@bmj.com.

Visit casereports.bmj.com for more articles like this and to become a Fellow 